\title{
Alphafetoprotein and neural tube defects
}

\author{
D. J. H. BROCK \\ From the Department of Human Genetics, University of Edinburgh, Western General Hospital, Edinburgh
}

\section{The Neural Tube Defects}

The neural tube defects (NTD) are a group of congenital malformations which are depressingly familiar to many obstetricians in the UK. Despite intensive investigation, their basic aetiology remains unknown. It seems probable that genetic factors are involved, interacting with environmental agents early in gestation to prevent closure of the neural tube. The number of the mutant genes is unknown, though it is probable that there is more than one locus (Carter, 1974). The environmental factors are also obscure in spite of recent attempts to implicate blighted potatoes (Renwick, 1972) and other common components of the mother's diet (Knox, 1972). Approaches to the prevention of spina bifida, anencephaly and hydrocephaly have thus been foiled by the inability to locate any of the causative agents needed in constructing a systematic epidemiology.

The two commonest forms of NTD are anencephaly and spina bifida cystica. Anencephaly is a lethal condition in which the brain is amorphous and the vault of the skull absent; if often occurs in association with spina bifida. Spina bifida cystica is a midline defect of the spine in which there is an external saccular protrusion. If the protrusion contains meninges and spinal fluid but no neural elements, it is referred to as a meningocele; if spinal cord and nerves are included in the sac, it is called a myelomeningocele or myelocele (Warkany, 1971). Only a small minority of cases of spina bifida cystica are meningoceles, a comparatively benign condition (Laurence, 1974). Thus the most common of these defects compatible with survival is the severe and often crippling myelocele spina bifida, more often than not associated with hydrocephalus. Less common to rare NTD are syringomyelocele, encephalocele, iniencephaly, exencephaly and uncomplicated hydrocephalus.

The incidence of neural tube defects has great geographical variation. High rates are found in Britain and Ireland, intermediate rates in other parts of Europe and North America and low rates in Africa, Asia and South America (Carter, 1974). In most surveys the number of cases of anencephaly has been approximately the same as those of spina bifida. The highest incidence areas are Northern Ireland $(7 \cdot 2 / 1000)$, Wales $(5 \cdot 8 / 1000)$, Scotland $(5 \cdot 6 / 1000)$ and the Republic of Ireland $(4 \cdot 8 / 1000)$, while England has an overall rate of 4 per 1000 (Renwick, 1972). With the possible exception of the anatomical defects of the heart, neural tube defects are thus the commonest of the serious congenital malformations.

If a mother has already had a child with spina bifida the risk of recurrence for each subsequent child is about one in forty. There is, however, an equal risk that the next child will be an anencephalic, so that the overall recurrence risk of NTD is about one in twenty or five percent. The same situation applies if the index child is an anencephalic (Laurence, 1969). For the mother with two previous affected children, whether they both be spina bifidas, both anencephalics or one of each, the recurrence risk rises to over $10 \%$ (Carter and Roberts, 1967). These calculations are based on empirical data from retrospective surveys and are probably minimal; other categories of risk are shown in table I.

The severity of neural tube defects ranges in a continuum from the still-born anencephalic through to the minimally affected meningocele spina bifida. Though it is often argued that anencephalics present little burden to their families, it must be remembered that there is a chance that the next child may have spina bifida. In high incidence communities where knowledge of neural tube malformations is part of folklore such pregnancies are times of great anxiety. As any obstetrician knows, there is a great demand for a safe and reliable method of prenatal diagnosis which will prevent the recurrence of this type of family tragedy. Recent discoveries of the potential of amniotic fluid and serum alphafetoprotein measurements suggest that this demand can now largely be satisfied.

\section{Alphafetoprotein}

In 1956 Bergstrand and Czar discovered a new protein in the serum of early human fetuses. It had $\alpha_{1}$-electrophoretic mobility and was not detectable 


\begin{tabular}{lcl}
\hline Family History & Estimated Risk (\%) & Reference \\
\hline One child with NTD & 5 & Laurence (1969) \\
Two children with NTD & 10 & Carter and Roberts (1967) \\
Three children with NTD & 21 & Smith (1973) \\
Parent with NTD & 3 & Carter and Evans (1973) \\
Parent and child with NTD & 13 & Smith (1973) \\
One child with multiple vertebral anomalies & 5 & Wynne-Davies (1975) \\
\hline
\end{tabular}

Table I Calculated risk of a mother having a child with a neural tube defect in various family situations

in adult serum and so was given the name alphafetoprotein (AFP), or more correctly alpha ${ }_{1}$-fetoprotein. An antiserum against AFP could be raised by immunizing experimental animals with fetal or newborn cord serum and by absorbing the resulting polyspecific immune serum with adult serum. This absorption removed all the antisera except that directed against AFP and produced a monospecific antiserum suitable for quantitative assays of AFP.

Alphafetoprotein is present in the sera of human fetuses from as early as four weeks of gestation (Seppälä and Ruoslahti, 1973a). Concentrations rise quite rapidly reaching a peak at the end of the first trimester, where levels of up to $4 \mathrm{mg} / \mathrm{ml}$ have been found (Gitlin and Boesman, 1966; Brock, 1974a). Thereafter, though net AFP synthesis remains constant until about the 30th week of life in utero, the rapidly expanding fetal blood volume causes a steady decline in concentration (Gitlin and Boesman, 1967). After the 30th week AFP synthesis decreases and by 6 months of age concentrations are not greatly different from the $10-20 \mathrm{ng} / \mathrm{ml}$ level found in the normal adult. This abrupt change to a concentration one hundred thousanth of that found in the 13-week fetus has justified the name alphafetoprotein for a protein which in the most rigorous sense is not truly fetospecific. The biological function of AFP is still not known.

Currently all measurements of AFP are based on its reaction with specific anti-AFP serum. For quantitation of the $\mathrm{mg} / \mathrm{ml}$ concentrations in fetal serum and the $\mu \mathrm{g} / \mathrm{ml}$ concentrations in second trimester amniotic fluids immunodiffusion and immunoelectrophoretic procedures are suitable. The 'rocket' or Laurell immunoelectrophoretic technique illustrated in fig 1 is the most widely used and satisfactory procedure for measuring AFP in amniotic fluids from diagnostic amniocenteses. In maternal serum where concentrations are in the $\mathrm{ng} /$ $\mathrm{ml}$ range, more sensitive techniques are necessary. If large numbers of samples are to be assayed the most suitable procedure is radioimmunoassay, though this requires a supply of purified AFP and facilities for radiolabelling with $125 \mathrm{I}$, and is thus not within the scope of many routine clinical laboratories. However, this difficulty is now being circumvented by the introduction of commercial radioimmunoassay test kits.

\section{Amniotic Fluid and the Prenatal Diagnosis of NTD}

The discovery of greatly increased concentrations of AFP in the amniotic fluids surrounding fetuses with neural tube defects stemmed from earlier observations of elevated bilirubin levels in full-term fluids of anencephalic infants (Cassady and Cailliteau, 1967). Bilirubin, however, could derive from either the maternal or fetal circulations, and as a comparatively low molecular weight compound would be expected to have a rapid turnover. There seemed little profit to be gained in pursuing bilirubin concentrations as a marker for the early prenatal diagnosis of NTD. A more effective marker would have to be of high molecular weight, unambiguously fetal in origin and measurable by a simple and specific procedure. An obvious candidate was AFP.

In the original publication Brock and Sutcliffe (1972) collected 37 third trimester amniotic fluids from pregnancies where the outcome had been an infant with spina bifida, anencephaly or hydrocephaly and showed that AFP concentrations were greatly increased in a large majority of these. One amniotic fluid from a myelocele spina bifida at 13 weeks and one from an anencephalic at 18 weeks, reported subsequently by Brock and Scrimgeour (1972), had AFP concentrations which were more than five times the upper limit of the normal range, thus predicting the usefulness of the method in early diagnosis. These findings were confirmed in another retrospective study (Nevin et al, 1973), and in May 1973 Lorber et al reported a prospective diagnosis of anencephaly based on amniotic fluid AFP (supported by ultrasonography and $x$-ray examination) which was followed by termination of the pregnancy and confirmation of the findings. Shortly thereafter Allan et al (1973) successfully diagnosed and aborted two cases of spina bifida on the basis of AFP concentrations without the aid of other physical measurements. Since then reports have followed hard and fast (Seller et al, 1973; Field et al, 1973; Milunsky and Alpert, 1974; Nevin et al, 1974; Brock et al, 1975b; Stewart et al, 1975), 


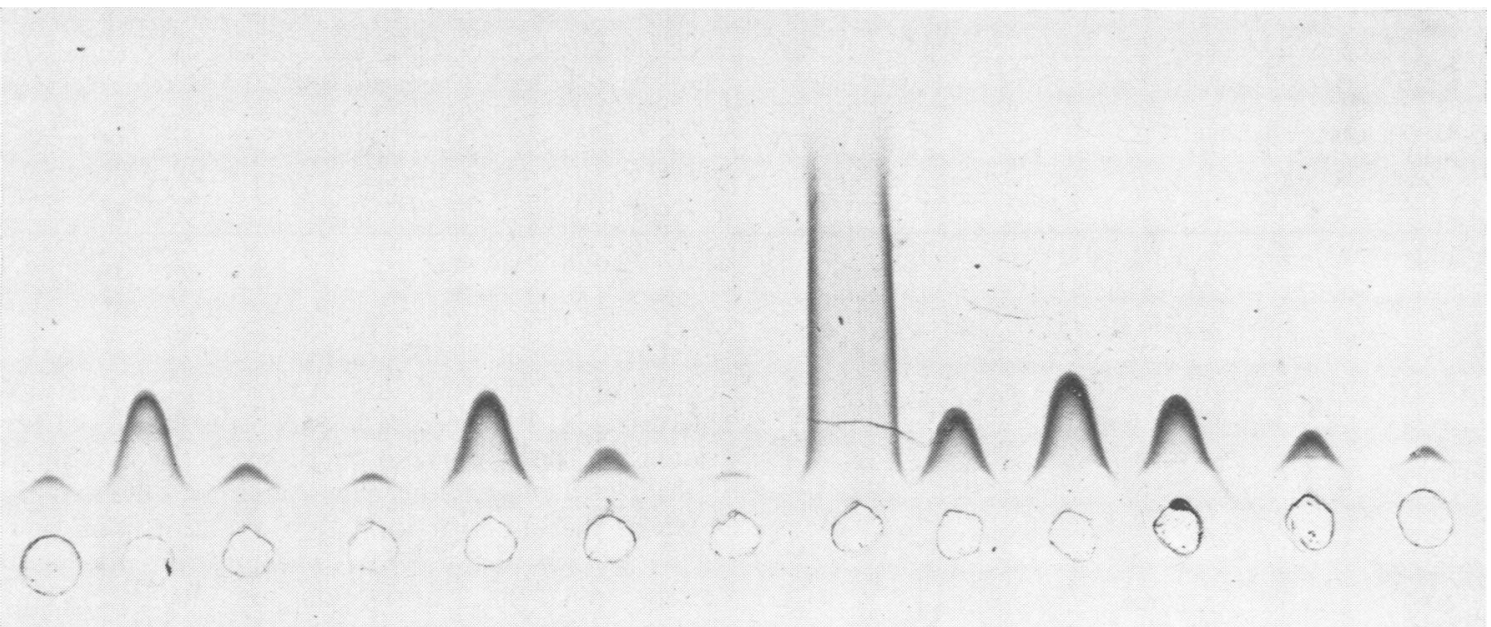

Fig 1 'Rocket' technique for measuring amniotic fluid AFP. Areas under the peaks are proportional to the amount of AFP in the sample. Amniotic fluid from a pregnancy where the fetus had spina bifida is shown in the eighth well from the left.

and amniotic fluid AFP testing is now widely offered at genetic counselling clinics in the UK (Brock, 1974b) and is begining to appear in the USA.

As a diagnostic test applied early in pregnancy it has proved remarkably specific. In a series of 520 samples taken between the eighth and 24th weeks of gestation, Brock et al (1975b) found only three marginal false positives (defined as an abnormal AFP value in the absence of a severe congenital malformation), one of these being in a twin pregnancy and two in pregnancies affected by rhesus isoimmunization. In 320 amniotic fluids between 11 and 25 weeks of gestation Stewart et al (1975) found no false positives. Early studies showed that when amniotic fluids were aspirated from the intact sacs of spontaneous abortions, the AFP concentrations were often substantially raised even when the fetus was anatomically and chromosomally normal (Allan et al, 1973; Seller et al, 1974a). This suggested that intrauterine death (missed abortion) might be detectable by raised AFP concentrations in amniocentesis samples and this now appears to be the case (Milunsky and Alpert, 1974). However, the time span between the actual fetal death and a substantial rise in the AFP concentration is not clear, and for this reason it remains important that the fetal heart be listened for both before and after amniocentesis.

A number of other fetal abnormalities where amniotic fluid AFP has been found to be increased are shown in table II. However, the observations may be regarded as being reasonably certain only for congenital nephrosis (Kjessler et al, 1975a and b).
In several cases the data are obtainable only late in pregnancy, eg, of Fallot's tetralogy and oesophageal atresia, and may not apply to the gestational period when diagnostic amniocentesis is carried out. In other situations, such as exomphalos (Brock et al, 1975b; Nevin and Armstrong, 1975) and duodenal atresia (Seppälä, 1975; Weinberg et al, 1975), there is disagreement as to whether all cases will show elevated AFP values. The findings on Turner's syndrome, made in amniotic fluid aspirated from the sacs of spontaneous abortions (Seller et al, 1974a), have not been confirmed in a single amniocentesis sample (Milunsky and Alpert, 1974).

The conditions listed in table II are all serious and therefore unlikely to compromise the validity of terminating pregnancy because of a high AFP value. The most probable cause of a false positive is contamination of the amniotic fluid with fetal blood, since fetal serum AFP concentrations are about 150 times those in the amniotic fluid at a corresponding gestation (Brock, 1974a) (fig 2). It is therefore important to screen any bloodstained amniotic fluids for the presence of fetal erythrocytes by the Kleihauer test or by searching electrophoretically for the characteristic band of haemoglobin F. A method for identifying haemoglobin in the cellfree supernatant at the same time as measuring AFP had been described (Brock, 1975a). The comparatively commonly found contamination of fluids by maternal blood does not influence AFP values (vide infra). Reports of normal fetuses associated with elevated amniotic fluid AFP (Campbell et al, 1975) 


\begin{tabular}{lll}
\hline Condition & Gestation & Reference \\
\hline Congenital nephrosis & 2nd trimester & Kjessler et al (1975a and b) \\
Exomphalos & 2nd trimester & Nevin and Armstrong (1975) \\
Sacrococcygeal teratoma & 2nd trimester & Schmid and Muhlethaler (1975) \\
Turner's syndrome & 1st trimester & Seller et al (1974a) \\
Duodenal atresia & 2nd trimester & Weinberg et al (1975) \\
Fallot's tetralogy & 3rd trimester & Seppälä (1975) \\
\hline
\end{tabular}

Table II Elevated amniotic fluid AFP concentrations associated with other defects

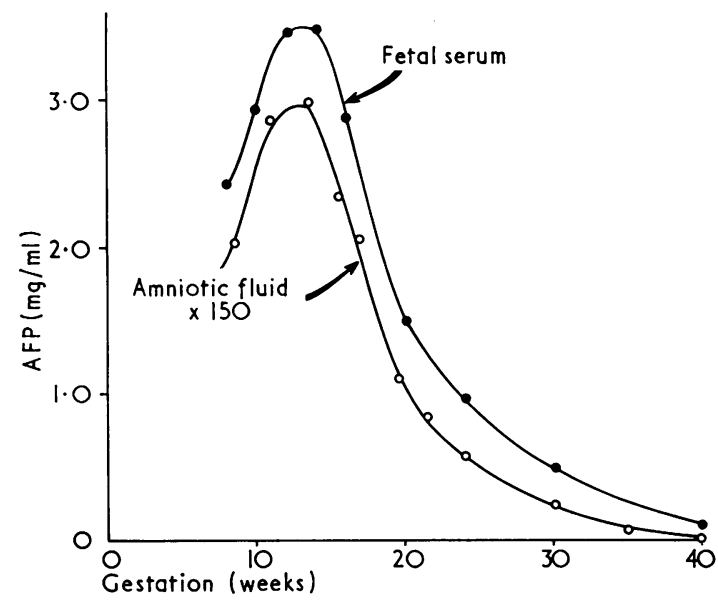

Fig 2 Comparison of AFP concentrations in fetal serum and amniotic fluid at different stages of gestation.

must be viewed with suspicion unless the identity of the blood in the contaminated fluid is established. Nonetheless there are several apparently authentic situations where abnormal AFP values have been associated with normal fetuses and where both fetal blood contamination and congenital nephrosis have been ruled out (personal communications from M. A. Ferguson-Smith and B. Norgaard-Pedersen). It must be concluded that amniotic fluid AFP tests, like most other diagnostic tests, will not be entirely free of genuine false positives.

In most cases the presence of a fetus with a NTD will be revealed early in pregnancy by a grossly elevated amniotic fluid AFP (fig 3). However, an exception must be made of those disorders where the lesion is closed, ie, covered by a full thickness of skin. An occipital encephalocele (Harris et al, 1974), a case of iniencephaly (Nevin et al, 1974) and several examples of closed meningocele spina bifidas(Stewart et al, 1975; Vince et al, 1975) have been reported. Uncomplicated hydrocephaly probably also belongs in this group, though so far only cases from late in pregnancy have been described (Brock and Sutcliffe, 1972; Seppälä and Unnerus, 1974). The assumption is that communication between the cerebrospinal fluid and the amniotic fluid is necessary to produce increased AFP concentrations. This is borne out by finding a rough correlation between the extent of lesions of the central nervous system and the magnitude of the amniotic fluid AFP concentration and also by very high AFP concentrations in fetal cerebrospinal fluid (Brock and Sutcliffe, 1972). The influence of membrane layers over the NTD lesion on the leakage of AFP into the amniotic fluid is still unclear, although the fetus shown in figure 4 had an amniotic fluid AFP at 18 weeks which was approximately four times the upper limit of normal.

As yet there is little published information on the significance of low AFP concentrations in amniocentesis samples. The blighted embryo or empty sac found occasionally in spontaneous abortion material may have AFP concentrations too low to be detected by 'rocket' electrophoresis, (Allan et al, 1973; Seller et al, 1974a; Brock et al, 1975b), but presumably few of these pregnancies would survive into the second trimester. Among diagnostic amniocentesis material most low AFP values signify an

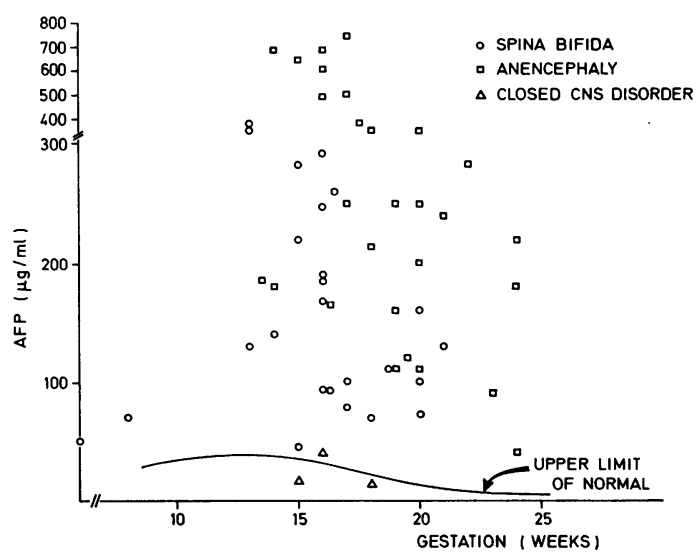

Fig 3 Amniotic fluid AFP concentrations from abnormal pregnancies. The upper limit of normal range is shown by the solid line. Data collected from the published literature. 


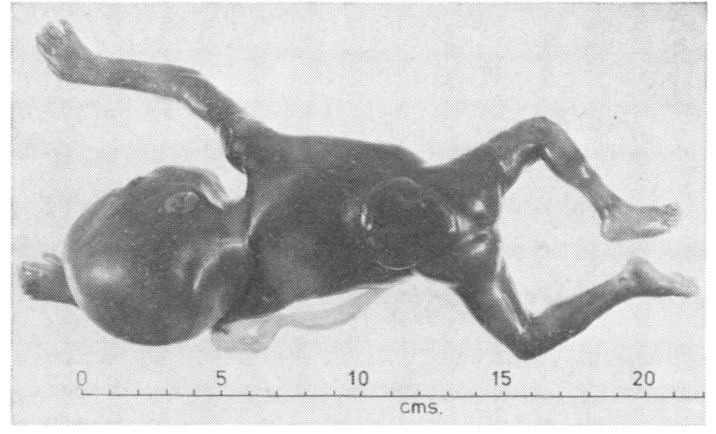

Fig 4 An 18-week fetus with spina bifida. The lesion was completely covered by membrane.

incorrectly specified gestation, sometimes wrong by as much as two months. Another occasional hazard is the misdirected tap which produces urine from the maternal bladder rather than amniotic fluid (Brock, 1975b).

\section{Prenatal Diagnosis of NTD Using Other Amniotic Fluid Parameters}

A number of other amniotic fluid parameters have been described which might be useful as complements to AFP assay in the early prenatal diagnosis of NTD (table III). Of these the low molecular weight compounds bilirubin, 5-hydroxyindole acetic acid and miscellaneous amino acids are not specific before the 20th week of pregnancy (Emery et al, 1974). The much-heralded $\beta$-trace protein (Macri et al, 1974a and b; Weiss et al, 1974) has now been discredited (Olsson et al, 1974; Brock and Olsson, 1976). Fibrinogen degradation products (Purdie et $a l, 1975)$ and the high molecular weight proteins $\alpha_{2}$-macroglobulin, $\beta$-lipoprotein (Brock, 1975a) and IgM (Cantuaria and Jones, 1975) all suffer from the disadvantage that contamination of amniotic fluid by maternal blood invalidates determinations. Quantitative assay of fetal macrophages among the amniotic fluid cells (Sutherland et al, 1973, 1975; Nelson et al, 1974 ) is likely to prove the most useful second-line indication of early neural tube defects.

\section{Screening for Neural Tube Defects by Maternal Blood AFP}

The hazards of second trimester amniocentesis are at present imprecisely defined. This means that in practice amniocentesis is only contemplated when the risk of fetal abnormality is substantial-say greater than $1 \%$. Even in very high incidence areas in the UK neural tube defects occur in fewer than one in a hundred births. Thus for the time being the diagnostic technique of amniotic fluid AFP measurement is restricted to those pregnancies where the

\begin{tabular}{|c|c|c|}
\hline Parameter & Comment & Reference \\
\hline $\begin{array}{l}\text { Bilirubin, 5-hydroxyindole acetic acid, } \\
\text { amino acids }\end{array}$ & Not useful early in pregnancy & Emery et al (1974) \\
\hline Fibrinogen degradation products & $\begin{array}{l}\text { Possibly useful if amniotic fluid AF not } \\
\text { contaminated }\end{array}$ & Purdie et al (1975) \\
\hline$\beta$-Trace protein & Discredited & Macri et al (1974) \\
\hline$a_{2}$-Macroglobulin & $\begin{array}{l}\text { Useful if amniotic fluid not } \\
\text { contaminated }\end{array}$ & Brock (1975b) \\
\hline$\beta$-Lipoprotein & Needs to be assessed & Brock (1975b) \\
\hline IgM & Doubtful & Cantuaria and Jones (1975) \\
\hline Fetal macrophages & Next best method to AFP & Sutherland et al $(1973,1975)$ \\
\hline
\end{tabular}

Table III Other amniotic fluid parameters claimed to be useful in the early prenatal diagnosis of NTD

\begin{tabular}{|c|c|c|}
\hline Reference & Spina Bifida ${ }^{1}$ & Anencephaly \\
\hline $\begin{array}{l}\text { Brock et al (1973) } \\
\text { Seller et al (1974b) } \\
\text { Harris et al (1974) } \\
\text { Wald et al (1974) } \\
\text { Brock et al }(1974) \\
\text { Cowchock and Jackson (1974) } \\
\text { Leek et al }(1974) \\
\text { Brock et al }(1975 \mathrm{a}) \\
\text { Vince et al }(1975) \\
\text { Leighton et al (1975) } \\
\text { Campbell et al }(1975) \\
\text { Total }\end{array}$ & $\begin{array}{l}3(0)^{1} \\
5(2) \\
3(2) \\
1(1) \\
12(4) \\
1(1) \\
5(4) \\
2(1) \\
32(15) \quad(47 \%)\end{array}$ & $\begin{array}{l}1(1)^{1} \\
2(2) \\
2(1) \\
1(1) \\
3(3) \\
1(1) \\
13(1) \\
3(3) \\
18(16) \\
44(39) \quad(89 \%)\end{array}$ \\
\hline
\end{tabular}

Table IV Number of cases of open spina bifida and anencephaly where maternal blood AFP was measured between 15 and 20 weeks of pregnancy

${ }^{1}$ Number of cases where AFP was outside the normal range shown in brackets. 
mother's risk is defined by the situations listed in table I. It can be calculated that at best this will allow detection of about $5 \%$ of the total of neural tube defects. Though it may be immensely valuable to a mother who knows from personal experience what a child with spina bifida entails, amniotic fluid AFP will have little effect on the overall incidence in the population of NTD. To make any real impact on the number of cases the diagnostic procedure must be released in the first instance from the restrictions imposed by amniocentesis.

Observations that maternal serum AFP concentrations are elevated in third trimester cases of fetal distress and intrauterine death (Seppälä and Ruoslahti, 1973b) stimulated investigations of its potential in the detection of neural tube defects. The first report of its use by Brock et al (1973) described a case of anencephaly where serum AFP was marginally elevated at 16 weeks and strongly elevated at 21 weeks. After ultrasound examination amniocentesis was performed, the amniotic fluid AFP measured, the pregnancy terminated and the diagnosis confirmed. The potential of this new method was initially disputed (Harris et al, 1974) but further data showed that some cases of both spina bifida and anencephaly could be detected by increased concentrations of AFP in the mother's blood early enough in gestation to allow a safe termination of pregnancy (Seller et al, 1974b; Brock et al, 1974; Wald et al, 1974).

It will be some time before the efficacy of this screening process can be precisely defined. However, two recently published large series allow some preliminary conclusions to be reached (Brock et al, 1975a; Leighton et al, 1975). It is clear that not all cases of NTD will be detectable and that fetuses with spina bifida will escape the screening net more easily than those with anencephaly. In particular the 'closed' spina bifidas, ie, where the lesion is covered with skin, will probably not be detectable. It is also clear that maternal blood AFP in normal pregnancy has such a wide range of values that the upper limit of normal must be defined as some percentile of the normal range or multiple of the median value. In practice the 95th, 98th and 99th percentiles have been most commonly employed. Since the maternal blood AFP measurement is only a preliminary to further investigations, the different percentiles selected demand rather different numbers of confirmatory amniocenteses. In many areas performing amniocentesis on $5 \%$ of all pregnancies (as would be indicated by use of the 95 th percentile) may place an unwelcome burden on obstetrical services.

It is also now generally agreed that the optimum time for maternal blood sampling is at the 15 th or 16 th week of pregnancy and that the method is ineffective before the end of the first trimester (Brock et al, 1975a; Vince et al, 1975; Leighton et al, 1975). The major area of dispute remains the proportion of cases of spina bifida which will be detectable by maternal blood screening, with Brock et al (1975a) taking a comparatively pessimistic view while Leighton et al (1975) are more optimistic. The cumulative total of published data (table IV) suggests that about $50 \%$ of open spina bifidas and nearly $90 \%$ of anencephalics will be detectable. It is quite possible that in carefully conducted prospective screening the proportion of spina bifidas will rise, and indeed this is the author's experience (Brock, unpublished). It is hoped that a recently instituted collaborative study in the UK will give a clear answer to this question.

While the mobidity risk of early amniocentesis remains unclear, unnecessary punctures of the amniotic sac must be kept to a minimum. One way of doing this is to try and recognize those situations where maternal serum AFP is raised in the absence of a NTD. The two best documented examples are multiple pregnancy and threatened abortion. It has been shown that twins will approximately double the median value of serum AFP, while triplets raise it even further (Garoff and Seppälä, 1973; Ishiguro, 1975; Wald et al, 1975). A multiple pregnancy can be confirmed or excluded by ultrasonography, and it is usual though not inevitable practice not to perform amniocentesis in this situation. A more difficult problem is that of threatened abortion. Serum AFP concentrations in mothers who are threatening to miscarry are usually greatly increased (Garoff and Seppälä, 1975; Seppälä and Ruoslahti, 1972, 1973b). It is not clear, however, when the serum AFP begins to rise and whether it reverts to normal values if the miscarriage is averted. Because of this uncertainty women with threatened abortions are usually excluded from confirmatory amniocentesis. Other situations where serum AFP may be raised in the second trimester are both less common and less well established, but probably include congenital nephrosis (Kjessler et al, 1975a), exomphalos (Nevin and Armstrong, 1975) and intrauterine death (Seppälä and Ruoslahti, 1973b).

\section{Conclusions}

Measurement of AFP in the amniotic fluid is now firmly established as a reliable indicator of a fetus with a neural tube defect early enough to allow a safe termination of pregnancy. Few genuine false positives have been observed and the indications are that high AFP levels are usually associated with serious fetal abnormalities. A limited number of false negatives have been recorded and it is probable that amniotic fluid AFP measurement will not 
allow detection of the comparatively rare closed lesions. The impact of these discoveries on the counselling of women who have already given birth to a child with a neural tube defect is considerable, and the anxiety of a mother caring for a severely crippled child with spina bifida who wishes to become pregnant again can now largely be allayed.

It is clear, however, that the overall incidence of neural tube abnormalities will not be substantially reduced by a method which depends in the first instance on amniocentesis. Preliminary screening of pregnancies by maternal blood AFP measurement should allow detection of about $90 \%$ of anencephalic fetuses and about $50 \%$ of fetuses with open forms of spina bifida. Mass application of screening could thus have a dramatic effect on the occurrence of neural tube defects in high incidence areas. However, this type of assay will also show elevated levels in a substantial number of pregnancies where there is no neural tube defect, and these will have to be excluded by amniocentesis and confirmatory amniotic fluid AFP determinations. Until the hazards of amniocentesis are more precisely defined, and until the detection efficiency of maternal blood AFP assay is improved, the introduction of mass screening will have to be approached with considerable caution.

\section{References}

Allan, L. D., Ferguson-Smith, M. A., Donald, I., Sweet, E. M., and Gibson, A. A. M. (1973). Amniotic-fluid alpha-fetoprotein in the antenantal diagnosis of spina bifida. Lancet, 2, 522-525.

Bergstrand, C. G., and Czar, B. (1956). Demonstration of a new protein in serum from the human fetus. Scand. $J$. clin. Lab. Invest., 8, 174.

Brock, D. J. H. (1974a). The molecular nature of alphafetoprotein in anencephaly and spina bifida. Clin. chim. Acta, 57, 315-320.

Brock, D. J. H. (1974b). Changing pattern of antenatal diagnosis. (Letter). Lancet, 2, 1077.

Brock, D. J. H. (1975a). Amniotic fluid alpha ${ }_{2}$-macroglobulin and the antenatal diagnosis of spina bifida and anencephaly. Clin. Genet., 8, 297-301.

Brock, D. J. H. (1975b). Antenatal misdiagnosis of neuraltube defects. (Letter). Lancet, 2, 495.

Brock, D. J. H., Bolton, A. E., and Monaghan, J. M. (1973). Prenatal diagnosis of anencephaly through maternal serum-alphafetoprotein measurement. Lancet, 2, 923-924.

Brock, D. J. H., Bolton, A. E., and Scrimgeour, J. B. (1974). Prenatal diagnosis of spina bifida and anencephaly through i maternal plasma-alpha-fetoprotein measurement. Lancet, 1, 767-769.

Brock, D. J. H., and Olsson, J. E. (1976). Comparison of alphafetoprotein and $\beta$-trace protein in the antenatal diagnosis of anencephaly and spina bifida. Clin. Genet., 9, 385-388.

Brock, D. J. H., and Scrimgeour, J. B. (1972). Early prenatal diagnosis of anencephaly. (Letter). Lancet, 2, 1252-1253.

Brock D. J. H., Scrimgeour, J. B., Bolton, A. E., Wald, N., Peto, R., and Barker, S. (1975a). Effect of gestational age on screening for neural-tube defects by maternal plasmaAFP measurement. Lancet, 2, 195-196.
Brock, D. J. H., Scrimgeour, J. B., and Nelson, M. M. (1975b). Amniotic fluid alphafetoprotein measurements in the early prenatal diagnosis of central nervous system disorders. Clin. Genet., 7, 163-169.

Brock, D. J. H., and Sutcliffe, R. G. (1972). Alpha-fetoprotein in the antenatal diagnosis of anencephaly and spina bifida. Lancet, 2, 197-199.

Campbell, S., Pryse-Davies, J., Coltart, T. M., Seller, M. J., and Singer, J. D. (1975). Ultrasound in the diagnosis of spina bifida. Lancet, 1, 1065-1068.

Cantuaria, A. A., and Jones, A. L. (1975). Immunoglobulin $M$ in human amniotic fluid and its possible associations with neural-tube malformations. Brit. J. Obstet. Gynaec., 82, 262-264.

Carter, C. O. (1974). Clues to the aetiology of neural tube malformations. Develop. Med. Child Neurol., 16, Suppl. 32, 3-15.

Carter, C. O., and Evans, K. (1973). Children of adult survivors with spina bifida cystica. Lancet, 2, 924-926.

Carter, C. O., and Roberts, J. A. F. (1967). The risk of recurrence after two children with central-nervous-system malformations. Lancet, 1, 306-308.

Cassady, G., and Cailliteau, J. (1967). The amniotic fluid in anencephaly. Amer. J. Obstet. Gynec., 97, 395-399.

Cowchock, F. S., and Jackson, L. G. (1974). Maternal serum-alpha-fetoprotein and anencephaly. (Letter). Lancet, $2,48$.

Emery, A. E. H., Brock, D. J. H., Burt, D., and Eccleston, D. (1974). Amniotic fluid composition in malformations of the fetal central nervous system. J. Obstet. Gynaec. Brit. Cwlth, 81, 512-516.

Field, B., Mitchell, G., Garrett, W., and Kerr, C. (1973). Amniotic alpha-fetoprotein levels and anencephaly. (Letter). Lancet, 2, 798,

Garoff, L., and Seppälä, M. (1973). Alpha fetoprotein and human placental lactogen levels in maternal serum in multiple pregnancies. J. Obstet. Gynaec. Brit. Cwlth, 80, 695-700.

Garoff, L., and Seppälä, M. (1975). Prediction of fetal outcome in threatened abortion by maternal placental lactogen and alpha fetoprotein. Amer. J. Obstet. Gynec., 121, 257261.

Gitlin, D., and Boesman, M. (1966). Serum a-fetoprotein, albumin, and $\gamma \mathrm{G}$-globulin in the human conceptus. $J$. clin. Invest., 45, 1826-1838.

Gitlin, D., and Boesman, M. (1967). Sites of serum afetoprotein synthesis in the human and in the rat. J. clin. Invest., 46, 1010-1016.

Harris, R., Jennison, R. F., Barson, A. J., Laurence, K. M., Ruoslahti, E., and Seppälä, M. (1974). Comparison of amniotic-fluid and maternal serum alpha-fetoprotein levels in the early antenatal diagnosis of spina bifida and anencephaly. Lancet, 1, 429-433.

Ishiguro, T. (1975). Serum a-fetoprotein in hydatidiform mole, choriocarcinoma, and twin pregnancy. Amer. J. Obstet. Gynec., 121, 539-541.

Kjessler, B., Johansson, S. G. O., Sherman, M., Gustavson, K. H., and Hultquist, G. (1975a). Alpha-fetoprotein in antenatal diagnosis of congenital nephrosis. Lancet, 1, 432-433.

Kjessler, B., Johansson, S. G. O., Sherman, M., Gustavson, K. H., and Hultquist, G. (1975b). Antenatal diagnosis of congenital nephrosis. (Letter). Lancet, 2, 553.

Knox, E. C. (1972). Anencephalus and dietary intakes. Brit. J. prev. soc. Med., 26, 219-223.

Laurence, K. M. (1969). The recurrence risk in spina bifida cystica and anencephaly. Develop. Med. Child Neurol., 11, Suppl, 20, 23-30.

Laurence, K. M. (1974). Fetal malformations and abnormalities. Lancet, 2, 939-942. 
Leek, A. E., Leighton, P. C., Kitau, M. J., and Chard, T. (1974). Prospective diagnosis of spina bifida. (Letter). Lancet, 2, 1511.

Leighton, P. C., Gordon, Y. B., Kitau, M. J., Leek, A. E., and Chard, T. (1975). Levels of alpha-fetoprotein in maternal blood as a screening test for fetal neural-tube defect. Lancet, 2, 1012-1015.

Lorber, J., Stewart, C. R., and Ward, A. M. (1973). Alphafetoprotein in antenatal diagnosis of anencephaly and spina bifida. (Letter). Lancet, 1, 1187.

Macri, J. N., Weiss, R. R., and Joshi, M. S. (1974a). Betatrace protein and neural-tube defects. (Letter). Lancet, 1 , 1109-1110.

Macri, J. N., Weiss, R. R., Joshi, M. S., and Evans, M. I. (1974b). Antenatal diagnosis of neural-tube defects using cerebrospinal-fluid proteins. Lancet, 1, 14-15.

Milunsky, A., and Alpert, E. (1974). The value of alphafetoprotein in the prenatal diagnosis of neural-tube defects. J. Pediat., 84, 889-893.

Nelson, M. M., Ruttiman, M. T., and Brock, D. J. H. (1974). Predictive value of amniotic-fluid macrophages in gross CNS defects. (Letter). Lancet, 1, 504.

Nevin, N. C., and Armstrong, M. J. (1975). Raised alphafetoprotein levels in amniotic fluid and maternal serum in a triplet pregnancy in which one fetus had an omphalocoele. Brit. J. Obstet. Gynaec., 82, 826-828.

Nevin, N. C., Nesbitt, S., and Thompson, W. (1973). Myelocele and alpha-fetoprotein in amniotic fluid. (Letter). Lancet, 1, 1383.

Nevin, N. C., Thompson, W., and Nesbitt, S. (1974). Amniotic fluid alpha-fetoprotein in the antenatal diagnosis of neural tube defects. J. Obstet. Gynaec. Brit. Cwlth, 81, 757-760.

Olsson, J. E., Sherman, M. S., and Kjessler, B. (1974). Beta-trace protein and neural-tube defects. (Letter). Lancet, 2, 347-348.

Purdie, D. W., Howie, P. W., Edgar, W., Forbes, C. D., and Prentice, C. R. M. (1975). Raised amniotic-fluid FDP in fetal neural-tube anomalies. Lancet, 1, 1013-1014.

Renwick, J. H. (1972). Hypothesis. Anencephaly and spina bifida are usually preventable by avoidance of a specific but unidentified substance present in certain potato tubers. Brit. J. prev. soc. Med., 26, 67-88.

Schmid, W., and Mühlethaler, J. P. (1975). High amniotic fluid alpha a $_{1}$-etoprotein in a case of fetal sacrococcygeal teratoma. Humangenetik, 26, 353-354.

Seller, M. J., Campbell, S., Coltart, T. M., and Singer, J. D. (1973). Early termination of anencephalic pregnancy after detection by raised alpha-fetoprotein levels. Lancet, 2,73 .

Seller, M. J., Creasy, M. R., and Alberman, E. D. (1974a). Alpha-fetoprotein levels in amniotic fluids from spontaneous abortions. Brit. med. J., 2, 524-525.

Seller, M. J., Singer, J. D., Coltart, T. M., and Campbell, S. (1974b). Maternal serum-alpha-fetoprotein levels and prenatal diagnosis of neural-tube defects. Lancet, 1, 428 429.

Seppälä, M. (1975). Fetal pathophysiology of human afetoprotein. Ann. N.Y. Acad. Sci., 259, 59-73.

Seppälä, M., and Ruoslahti, E. (1972). Radioimmunoassay of maternal serum alpha fetoprotein during pregnancy and delivery. Amer. J. Obstet. Gynec., 112, 208-212.

Seppälä, M., and Ruoslahti, E. (1973a). Alpha-fetoprotein: physiology and pathology during pregnancy and application to antenatal diagnosis. J. perinat. Med., 1, 104-113.

Seppälä, M., and Ruoslahti, E. (1973b). Alpha fetoprotein in maternal serum: a new marker for detection of fetal distress and intrauterine death. Amer. J. Obstet. Gynec., 115, 48-52.

Seppälä, M., and Unnerus, H. A. (1974). Elevated amniotic fluid alpha fetoprotein in fetal hydrocephaly. Amer. J. Obstet. Gynec., 119, 270-272.

Smith, C. (1973). Implications of antenatal diagnosis In Antenatal Diagnosis of Genetic Disease, edited by A. E. H. Emery, pp. 137-155. Churchill-Livingstone, Edinburgh and London.

Stewart, C. R., Ward, A. M., and Lorber, J. (1975). Amniotic fluid $a_{1}$-fetoprotein in the diagnosis of neural tract malformations. Brit. J. Obstet. Gynaec., 82, 257-261.

Sutherland, G. R., Brock, D. J. H., and Scrimgeour, J. B. (1973). Amniotic-fluid macrophages and anencephaly. (Letter). Lancet, 2, 1098-1099.

Sutherland, G. R., Brock, D. J. H., and Scrimgeour, J. B. (1975). Amniotic fluid macrophages and the antenatal diagnosis of anencephaly and spina bifida. J. med. Genet., 12, 135-137.

Vince, J. D., McManus, T. J., Ferguson-Smith, M. A., and Ratcliffe, J. G. (1975). A semi-automated serum alphafetoprotein radioimmunoassay for prenatal spina bifida screening. J. Obster. Gynaec. Brit. Cwlth, 82, 718-727.

Wald, N. J., Barker, S., Peto, R., Brock, D. J. H., and Bonnar, J. (1975). Maternal serum $\alpha$-fetoprotein levels in multiple pregnancy. Brit. med. J., 1, 651-652.

Wald, N. J., Brock, D. J. H., and Bonnar, J. (1974). Prenatal diagnosis of spina bifida and anencephaly by maternal serum-alpha-fetoprotein measurement: a controlled study. Lancet, 1, 765-767.

Warkany, J. (1971). Congenital Malformations. Year Book Medical Publishers, Chicago.

Weinberg, A. G., Milunsky, A., and Harrod, M. J. (1975) Elevated amniotic-fluid alphafetoprotein and duodenal atresia. (Letter). Lancet, $2,496$.

Weiss, R. R., Macri, J. N., Tejani, N., Tillitt, R., and Mann, L. I. (1974). Antenatal diagnosis and lung maturation in anencephaly. Obstet. and Gynec., 44, 368-372.

Wynne-Davies, R. (1975). Congenital vertebral anomalies: aetiology and relationship to spina bifida cystica. $J$. med. Genet., 12, 280-288. 